\title{
A Review on Industrial Cooling System
}

\author{
Shubham Shukla \\ M. Tech. \\ Truba Group of Institutes college \\ Bhopal, India \\ sshukla1109@gmail.com
}

\author{
Rajeev Arya \\ Director \\ Truba Group of Institutes college \\ Bhopal, India \\ aryarajeev25@yahoo.com
}

\author{
Nilesh Diwakar \\ HOD
}

Truba Group of Institutes college

Bhopal, India

nilesh.diwakar@trubainstitute.ac.in

\begin{abstract}
The modeling of the heating, ventilation, and air conditioning (HVAC) system is a prominent topic because of its relationship with energy savings and environmental, economic, and technological issues. The modeling of the HVAC system is concerned with the indoor thermal sensation, which is related to the modeling of building, air handling unit (AHU) equipment's, and indoor thermal processes. This paper shows the HVAC model and the Winter Air Conditioning System, Summer Air Conditioning System. Until now, many HVAC system modeling approaches are made available, and the techniques have become quite mature.
\end{abstract}

Keywords: HAVC, AHU, Temperature, physics based models.

\section{INTRODUCTION}

Thermal comfort is an essential factor that should be considered in building/office design process which can have a beneficial impact on the social and economic behavior aspects of people using these places. Comfortable climates can encourage the human for relaxation and can thus increase the commercial activity. Theoretical studies were mostly based on energy equations which are built in between human and environment and required very extensive mathematical work. Practical studies on the other hand were done by experimenting humans under various thermal environments, which were time consuming and could be misleading because of the personal opinions of people regarding to comfort. Compared those two methods, measuring thermal comfort by using simulation software gave the benefit of both by being able to simulate many conditions at once and carrying out the huge mathematical work by the aid of computers [1].

From the ASHRAE handbook various definitions can be found;
- The state of being content with the thermal environment

- Requirement of minimum effort for maintaining internal body temperature

- Conditions of being satisfied with the thermal environment

\section{Literature ReVIEW}

Cătălin George Popovici [1] The aim of the study is to simulate the functionality of an HVAC system in different situations, both in summer and in winter, using the special ANSYS-Fluent software. A 2D construction model was created and the simulation of the internal conditions was the main elements of the study. Indoor air temperature and speed are examined under different conditions. The results are presented in the form of diagrams / graphs and spectra of parameters of interest. Simulating the functionality of the HVAC system with ANSYS-Fluent provides important results for the scenario examined. It can be determined with certainty that the recently implemented HVAC system is doing its job and providing adequate comfort conditions in the amphitheater during the two seasons. Average speeds are slightly higher during the summer season because higher air flows are needed.

Jéssica Kuntz Maykot at el. [2] This article is intended to examine the effects of gender on thermal comfort requirements in office buildings. The data comes from 83 field studies conducted in 2014 in three office buildings in Florianopolis, in southern Brazil. There was no significant difference in the isolation of clothing for male and female subjects. Significant differences were observed in the central and air-conditioned building in terms of heat, preferably thermal, thermal acceptance and thermal comfort. In mixed-mode buildings, significant 
differences were observed in the thermal sensation and in the responses to the thermal preferences of male and female subjects.

Jindal A et al. [3] During the 2015/16 monsoon and the winter seasons, a field study was conducted to study the thermal environment and thermal comfort in naturally ventilated indoor classrooms (NV) of a composite state boarding school in the climatic zone of Ambala, India. A total of 640 responses were collected from 130 student's aged 10 to 18 in rural areas. An internal operating temperature of $27.1{ }^{\circ} \mathrm{C}$ was recorded as a neutral temperature. The results show that students' heat tolerance is quite high. To date, there are no climatic zones in India where thermal comfort standards exist for school classes. The results of this study should provide guidelines for India's specific thermal comfort standards for schools for energy efficient use.

Földváry V at el. [4] The ASHRAE Global Thermal Comfort Database II project was launched in 2014 under the direction of the University of California at the Berkeley Center for the Built Environment and the University of Sydney Indoor Environmental Quality Laboratory (IEQ). The exercise began with a systematic collection and harmonization of raw data from the past two decades of field studies on thermal comfort worldwide. The ASHRAE Global Thermal Comfort II database, now an online open source database, contains approximately 81,846 complete sets of objective observations on the indoor climate, along with subjective assessments of users of the exposed building. In addition, a web-based interactive visualization tool for thermal comfort has been developed, with which end users can explore data quickly and interactively.

M.T.H. Derks at el. [5] In research on internal comfort, the thermal well-being of nurses in hospitals is poorly studied. To fill this gap, a mixed method study was conducted in which the nursing staff seemed to be participating in the infirmaries. The answers were collected for three weeks in summer $(n=89)$ and four weeks in autumn $(\mathrm{n}=43)$. Analysis of the nurses' subjective comments and the thermal conditions measured inside showed that the existing thermal conditions (between 20 and $25^{\circ} \mathrm{C}$ ) on the 7-point ASHRAE scale caused a slightly warm thermal sensation. This led to somewhat unacceptable thermal comfort and a slightly disabled self-assessment of work performance. The results also showed that the optimal feeling of warmth for nurses - based on their thermal comfort needs and their performance at work - is "rather cool" rather than neutral.

Ricardo Forgiarini Rupp [6] In order to better understand this type of building and its influence on the thermal perception of residents, studies have been conducted on the thermal comfort of buildings in mixed mode. This work found no evidence that a single adaptive model is supported for mixed mode buildings. In natural ventilation mode, occupants adapt to internal temperature fluctuations, as predicted by adaptive thermal comfort theory. On the other hand, a weak adaptive relationship (indoor comfort temperature versus outdoor climate) was observed during air conditioning operation - for air conditioner operation without sacrificing thermal comfort, which could save energy. This work is a first step towards building an adaptive model of thermal comfort for the subtropical climate in Brazil.

\section{The Mathematical Model of the HVAC SYSTEM}

There are two types of the white-box or the mathematical model: the lumped and the distributed parameters. The main advantage of the lumped parameter model is that it is much easier to solve than the distributed model.

The mathematical models are very popular for the HVAC systems in representing the processing signal. The processes' signals are constructed based on physical and chemical laws of conservation, such as component, mass, momentum, and energy balance. These laws describe the linking between the input and the output which is transparently represented by a large number of mathematical equations. Furthermore, the mathematical model is a good tool to understand the behavior of the indoor condition by describing the important relationships between the input and the output of the HVAC system. In general, the modeling process of the HVAC systems leads to dynamic, nonlinear, and high-thermal inertia, pure lag time, uncertain disturbance factors, and very high-order models. The whole model can be described by several sub models to alleviate the complexity of the model [7]. These sub model processes are related to fluid flow and heatand-mass transfers between interfacing sub models, which can be governed by mass, momentum, and energy conservation principles. These principles are usually expressed by differential equations, which may be implemented by time domain or (frequency) domain, 
where the domain can be represented by a transfer function or a state-space function. The limitations of the early building mathematical models are mainly due to the limitation in the computer hardware since the models needed an intensive computational process. But the situation is changing as computational tools capacity has improved by the evolution in software and hardware of computers.

\section{AIR CONDITIONING AND ITS WORKING PRINCIPLE}

Nowadays, the air conditioning system is widely used both in the home and in a commercial environment. Air cooling or air conditioning is the process of removing heat and humidity from the inside to improve occupant comfort [8]. This process is often used to obtain a more comfortable indoor climate, typical of people.

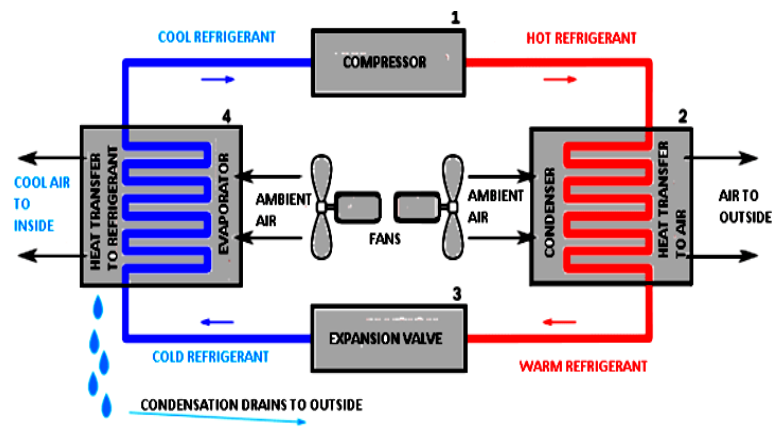

Fig. 1 working principle of air conditioning

The definition of air conditioning is a humidity, ventilation and temperature control system in a building or vehicle to generally maintain a cool atmosphere in warm conditions.

Although air conditioners can vary from model to model, they are available in all areas, from small units that can cool a small room to huge units installed on the roof of office towers and can cool an entire building.

\section{Winter Air Conditioning System}

Air conditioner working principle in winter air conditioning system, the air is burnt and heated, which is generally followed by humidification.

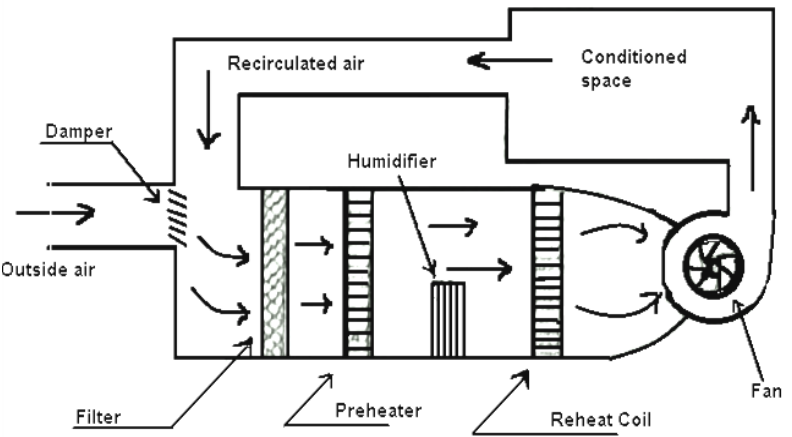

Fig. 2 winter air conditioning system

The outside air flows through a shutter and mixes with the circulating air. The mixed air is passed through a filter to remove dirt, dust and contaminants.

The air now passes through a preheating coil to prevent freezing of the water and to control the evaporation of water in the humidity of the air. The air then passes through a post-heating coil to bring the air to the expected temperature of the dry bulb.

Air conditioning is now conducted into the air conditioned room by a fan. Part of the air in the air-conditioned room is released into the atmosphere by the exhaust fans. The remaining part of the used air is recycled and this is repeated several times.

\section{Summer Air Conditioning System}

In this system, the air is cooled and generally dehumidified. Schematic for a typical summer air conditioning system is arranged.

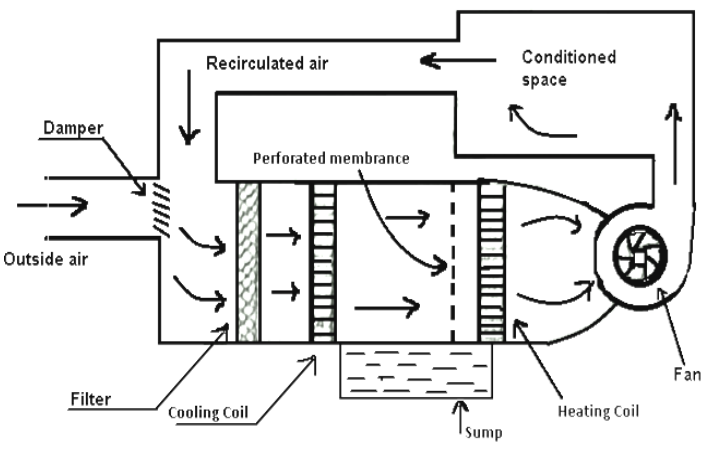

Fig. 3 summer air conditioning system

The outside air circulates through the shutter and mixes with the circulating air (which comes from the airconditioned room). The mixed air is passed through a filter to remove dirt, dust and contaminants. 
Air now flows through a cooling coil. The battery temperature is much lower than the required dry bulb temperature of the air in the air conditioned room.

The cooled air passes through a perforated membrane and loses its moisture in the condensate that accumulates in the cup. The air then passes through a heating coil which slowly heats the air [9].

This is done to bring the air to the expected temperature of the dry bulb and relative humidity. Air conditioning is now directed into the air conditioned room by a fan. From the air-conditioned room, part of the air used is released into the atmosphere by the exhaust fan. The remaining air is conditioned again and this is repeated several times.

The outside air is sucked in and mixed with the circulating air in order to cause the loss of the conditioned air by the exhaust fan of the air-conditioned room.

\section{YEAR-Round AIR CONDITIONING System}

Air conditioning units open all year round should have summer and winter air conditioning systems. The wiring diagram for modern summer air conditioning is organized all year round.

Operating principle of the air conditioning system in the air conditioning system all year round. In this, the outside air flows through the shutter and mixes with the circulating air. The mixed air is passed through a filter to remove dirt, dust and contaminants.

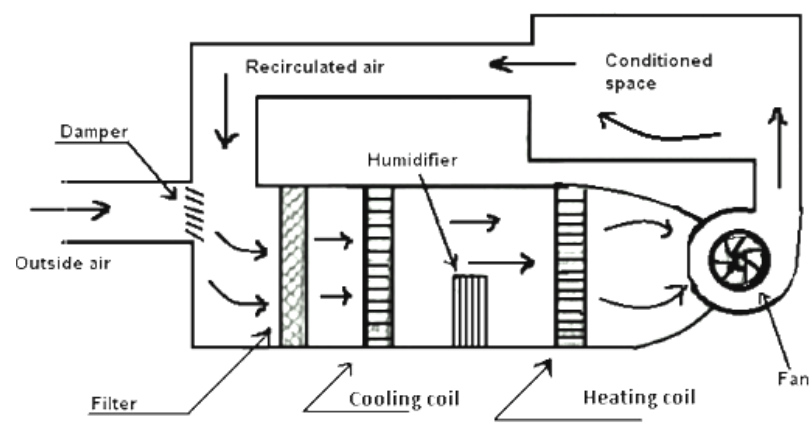

Fig. 4 Year round air conditioning system

In a summer air conditioning system, cooling is used to cool the air to the desired valve. Dehumidification is achieved by operating the cooling coil at a temperature below the dew point temperature.

In a winter air conditioning system, the cooling coil is turned off and the heating coil heats the air. The spray humidifier is also used to humidify the air during the dry season.

\section{Conclusion}

This paper reviewed previous work on modeling HVAC systems to help researchers develop the best and most rational solutions to current problems in modeling HVAC systems. This document shows the HVAC model and the winter air conditioner, the summer air conditioner. So far many approaches to modeling HVAC systems have been proposed and the techniques are quite mature.

\section{REFERENCES}

[1] Cătălin George Popovici "HVAC system functionality simulation using ANSYS-Fluent" Sustainable Solutions for Energy and Environment, Bucharest, Romania, Energy Procedia vol. 112 (2017) page from $360-365$.

[2] Jéssica Kuntz Maykot at el. "Assessment of gender on requirements for thermal comfort in office buildings located in the Brazilian humid subtropical climate" Contents available at Science Direct Energy and Buildings 158 (2018) 1170-1183.

[3] Jindal A "Thermal comfort study in naturally ventilated school classrooms in composite climate of India", Building and Environment Accepted Date: 26 May 2018.

[4] Földváry V at el. "Development of the ASHRAE Global Thermal Comfort Database II", Building and Environment Accepted Date: 12 June 2018, doi: 10.1016/j.buildenv.2018.06.022.

[5] M.T.H. Derks at el. "Understanding thermal comfort perception of nurses in a hospital ward work environment" Building and Environment 140 (2018) 119-127.

[6] Ricardo Forgiarini Rupp, Richard de Dear \& Enedir Ghisi "Field study of mixed-mode office buildings in Southern Brazil using anadaptive thermal comfort framework "Energy and Buildings 158 (2018) 1475-1486.

[7] P. S. Agachi, Z. K. Nagy, M. V. Cristea, and A. I. Lucaci, Model Based Control, John Wiley \& Sons, New York, NY, USA, 2006.

[8] Shilei Lu, Bo Pang, Yunfang Qi \& Kun Fang "Field study of thermal comfort in non-air-conditioned buildings in a tropical island climate" Applied Ergonomics 66 (2018) 89e97.

[9] Elena Barbadilla Martat el. "Assessment of thermal comfort and energy savings in a Peld study on adaptive comfort with application for mixed mode of offices, Energy \& Buildings Accepted date: 16 February 2018. 